12 | InterAção

\title{
OS CONFLITOS CONTEMPORÂNEOS E A TEORIA DE SUN TZU: NOVAS ABORDAGENS, ANTIGOS POSTULADOS
}

\author{
Sergio Ricardo Reis Matos ${ }^{1}$
}

Marcelo Bastos de Souza²

Paulo Eduardo de Mello Perezino ${ }^{3}$

\section{Resumo}

O cenário internacional da atualidade apresenta-se bastante complexo, notadamente a partir da década de 1990, com a derrocada da União Soviética e a consequente quebra da ordem mundial bipolar. Ainda assim, a transformação dos Estados Unidos da América na única superpotência mundial não trouxe a paz esperada ao sistema internacional, verificando-se o surgimento de diversos conflitos. Os Estados passaram a adaptar suas estratégias militares às demandas advindas dessa nova conjuntura. Nesse contexto, o presente trabalho tem por objetivo geral analisar a aplicabilidade da teoria da guerra proposta por Sun Tzu aos conflitos contemporâneos. Para alcançar esse fim, foram traçados os seguintes objetivos específicos: estudar os conceitos e as estratégias conexas às abordagens abrangentes dos conflitos contemporâneos; estudar a escola estratégica chinesa, destacando a teoria da guerra de Sun Tzu; discutir as aproximações dos postulados de Sun Tzu aos conflitos contemporâneos. Utilizou-se uma abordagem qualitativa, valorizando a epistemologia da complexidade. As categorias estudadas foram: estratégia indireta; conhecimento do inimigo; dissimulação e previsão; tempo; preparação do campo de batalha e liderança. A revisão da literatura foi feita por meio de pesquisa bibliográfica. A discussão compreende a análise de conteúdo e a triangulação das entrevistas e de textos dos novos conflitos. Por fim, pôde-se constatar a validade e a aplicabilidade das teorias de Sun Tzu aos conflitos contemporâneos, tornando sua obra uma leitura recomendada para qualquer estrategista do século XXI.

1 Exército Brasileiro. Colaborador do Laboratório de Estudos de Sociedade e Defesa (LABDEF) da Escola Superior de Guerra. Mestre em Relações Internacionais pela Universidad Mayor de San Andrés. Especialista em Língua Portuguesa.

2 Exército Brasileiro. Instituto Meira Mattos da Escola de Comando e Estado-Maior do Exército. Mestre em Ciências Militares pelo Instituto Meira Mattos. Especialista em História Militar.

${ }^{3}$ Exército Brasileiro. Mestre em Operações Militares pela Escola de Aperfeiçoamento de Oficiais. Especialista em Direito Militar. Bacharel em Direito. 
13 | InterAção

Palavras-chave: abordagens abrangentes, conflitos contemporâneos, estratégia indireta, Sun Tzu.

\begin{abstract}
The current international scene is rather complex, especially since the 1990s, with the collapse of the Soviet Union and the consequent breakdown of bipolar world order. The transformation of the United States of America in the unique global superpower has not brought expected peace to the international system, which can be verified with various conflicts. Since then, the States have to adapt their strategies to the military demands arising from this new situation. In this context, this work aims to analyze the applicability of the theory of war proposed by Sun Tzu in the context of contemporary conflicts. To achieve this purpose, the following specific objectives were aimed: to study the concepts and strategies related to the comprehensive approaches of contemporary conflicts; to study Chinese strategy, highlighting the Sun Tzu's theory of war; and to discuss the influence of Sun Tzu's assumptions in the contemporary conflicts. A qualitative approach was used, valuing the epistemology of complexity. The categories considered were indirect strategy, knowledge of the enemy; concealment and forecasting, time, preparation of the battlefield, and leadership. A literature review was made by means of bibliographical investigation. The discussion includes the content analysis and triangulation of interviews and texts about new conflicts. Finally, we infer there is validity and applicability of the theories of Sun Tzu to contemporary conflicts, recommending his work to any strategist of the XXI century.
\end{abstract}

Keywords: comprehensive approaches, contemporary conflicts, indirect strategy, SunTzu.

\title{
1. INTRODUÇÃO
}

O atual cenário mundial de conflitos é complexo: os Estados não são mais os únicos protagonistas dos conflitos contemporâneos (KALDOR, 1999). A maioria desses conflitos, particularmente após a queda do muro de Berlim4,

\footnotetext{
${ }^{4}$ Com base em Pizarro (2006), este trabalho procurou analisar os conflitos contemporâneos a partir do fim da Guerra Fria.
} 
14 InterAção

possui variáveis domésticas ${ }^{5}$ como causas principais (PIZARRO, 2006).

A globalização potencializou a periculosidade e transformou a natureza dessas variáveis domésticas. Nas palavras de Keohane (2002), essas variáveis ganharam o status de ameaças transnacionais, pois podem atuar em qualquer local, sendo provenientes de qualquer parte do mundo.

São, portanto, ameaças incertas, difusas e de natureza variada que, em geral, não cumprem a destinação tradicional dos conflitos, ou seja, a imposição da vontade política ao oponente, como teorizou Clausewitz (MEI, 2013; SAINTPIERRE, 2010).

Logo, grupos terroristas, civilizações em choque, insurgências, guerras assimétricas e outros atores e formas de conflito, no atual cenário de disputa de poder, causam instabilidade nas relações internacionais (VISACRO, 2009), provocam a ampliação e o aprofundamento das abordagens sobre guerra e paz (BUZAN; HANSEN, 2012) e exigem mudanças nas concepções estratégicas clássicas.

Em consequência, as concepções estratégicas contemporâneas estão abandonando a sistemática focada em inimigos específicos, passando a valorizar o planejamento por capacidades. O fundamental "é a forma 'como' o oponente vai atuar e com que meios, e não tanto a sua identificação (quem), nem o momento da sua ação (quando)" (LEITE, 2011, p. 2). Assim, avalia-se o desenho pelo qual forças oponentes ou adversas (Estados, paramilitares, criminosos, terroristas, eventos naturais) são capazes de afetar a segurança e a defesa dos indivíduos, instituições, organizações e Estados.

Um paradoxo anacrônico surge nesses novos tempos: os conflitos

${ }^{5}$ Na seção Revisão de Literatura, essas variáveis domésticas são mais detalhadas, conforme Manwaring (2011). 
15 InterAção

contemporâneos são complexos e inconstantes, tal como ditava o filósofo chinês Sun Tzu, há mais de 2500 anos: "assim como a água tem várias formas, a guerra não possui condições constantes"' (KANE, 2007, p. 1).

O livro de Sun Tzu é um dos mais antigos postulados sobre estratégia militar do mundo. Seu trabalho data do período dos estados beligerantes antigos, entre os anos de 403 e 221 a.C., época de profundas mudanças na sociedade, cultura e pensamento orientais, o que originou a nacionalidade chinesa (SUN-ZI, 2001).

O estudo de sua teoria é matéria discutida em várias academias militares ao redor do mundo (KANE, 2007). Ao comparar os pressupostos de Clausewitz aos de Sun Tzu no contexto da guerra moderna, McNeilly (2009) afirma que, conquanto existam compatibilidades de pensamento, há diferenças marcantes que são extremamente úteis no atual contexto.

Sun Tzu não defendia a destruição completa do oponente pela guerra total, como afirmava Clausewitz. Defendia, sim, a guerra limitada, em que se respeitassem "as regras humanitárias que limitam o sofrimento humano e a destruição física” (MCNEILLY, 2009, p. 254): “Sun Tzu prefere errar por excesso de cautela" (KANE, 2007, p. 117). Em razão das novas demandas dos conflitos contemporâneos, McNeilly postula a hipótese de que os líderes ocidentais devem procurar a orientação em Sun Tzu.

A valorização desses pressupostos coincide com a (re)emergência da China como importante ator no cenário internacional. Essa grande nação asiática é a segunda maior potência econômica mundial, possui poder de veto no Conselho de Segurança das Nações Unidas, abarca a maior população do globo e detém armamentos atômicos, o que, na visão realista tradicional, demonstra seu atual poder. Na política internacional, de acordo com Duarte 
16 | InterAção

(2012) e Kane (2007), a China possui estratégias, diretas e indiretas, que são influenciadas pela teoria de Sun Tzu.

Nesse contexto, formulou-se a problemática central deste trabalho: quais seriam as contribuições mais significativas da escola estratégica chinesa, a partir da teoria de Sun Tzu, para o pensamento estratégico de emprego militar contemporâneo?

Logo, o objetivo geral é analisar a aplicabilidade da teoria da guerra proposta por Sun Tzu aos conflitos contemporâneos. Para tanto, os objetivos específicos são:

- estudar os conceitos e as estratégias conexas às abordagens abrangentes ${ }^{6}$ dos conflitos contemporâneos;

- estudar a escola estratégica chinesa, destacando a teoria da guerra de Sun Tzu;

- discutir as aproximações dos postulados de Sun Tzu aos conflitos contemporâneos.

\section{PROCEDIMENTOS METODOLÓGICOS}

O trabalho foi elaborado a partir de uma abordagem qualitativa, valorizando a epistemologia da complexidade, pois os cenários dos conflitos contemporâneos são influenciados por fatos que tendem a modificar prospecções (BOUSQUET, 2009).

${ }^{6}$ Do inglês comprehensive approach, conforme tradução da UNESP de Buzan e Hansen (2012). 
17 | InterAção

Analisando ainda que, no estudo de ciências que englobam relações internacionais, essa complexidade dificulta generalizações (BAUMAN, 2004); não há como dimensionar uma resposta lógica para a problemática, ou seja, não há hipóteses. Para nortear o trabalho, aceitou-se a premissa de que a teoria da guerra de Sun Tzu influencia concepções estratégicas nos conflitos contemporâneos.

Considerando que a filosofia de Sun Tzu possui postulados estratégicos, operacionais e táticos, o presente estudo priorizou os estratégicos e aqueles operacionais ou táticos que possuem consequências estratégicas.

Assim delimitada, a pesquisa foi delineada conforme os passos de Frigotto (2008): (1) definição da problemática, (2) resgate da produção teórica, (3) método de organização para coleta e análise, (4) análise de dados, (5) síntese.

Com a problemática definida, o resgate da produção teórica teve por objetivo “(...) identificar as diferentes perspectivas de análise, as conclusões a que se chegou pelo conhecimento anterior e a indicação das premissas do avanço do novo conhecimento" (FRIGOTTO, 2008, p. 88).

O trabalho também foi bibliográfico, descritivo, exploratório e de campo, de acordo com as classificações de Marconi e Lakatos (2003). Foi bibliográfico, pois se constituiu da análise de conteúdo de livros, artigos científicos, ensaios, discursos publicados e informações em jornais e revistas. Foi descritivo e exploratório, pois, desde um estudo descritivo e crítico da teoria, procurou avançar na produção do conhecimento sobre o pensamento estratégico.

A pesquisa de campo foi realizada por meio de entrevistas estruturadas com especialistas. Foram adotados os seguintes códigos: 
18 InterAção

Quadro 1. Entrevistados.

\begin{tabular}{|l|l|}
\hline Código & Especialidades \\
\hline M1 & $\begin{array}{l}\text { General de Exército. Foi Secretário de Política, Estratégia e Relações Internacionais do } \\
\text { Ministério da Defesa e Coordenador do Curso de Política, Estratégia e Alta Administração do } \\
\text { Exército da Escola de Comando e Estado-Maior do Exército. }\end{array}$ \\
\hline M2 & $\begin{array}{l}\text { General de Exército. Foi Comandante Militar de Área, adjunto do Adido do Exército na China } \\
\text { e Chefe da Assessoria Parlamentar do Exército. }\end{array}$ \\
\hline M3 & $\begin{array}{l}\text { Coronel. Foi adido do Exército em país sul-americano. Foi supervisor da Defesa Aeroespacial } \\
\text { do Brasil. }\end{array}$ \\
\hline M4 & $\begin{array}{l}\text { Diplomata. Mestre em Diplomacia. Investigador na área de segurança e defesa. Trabalhou na } \\
\text { implementação do planejamento estratégico no Ministério da Defesa. }\end{array}$ \\
\hline M5 & $\begin{array}{l}\text { Doutora em Sociologia do Desenvolvimento. Professora e orientadora de Pós-graduação em } \\
\text { Relações Internacionais. Estuda segurança internacional e o papel das potências emergentes, } \\
\text { incluindo Brasil e China. }\end{array}$ \\
\hline
\end{tabular}

Fonte: elaboração própria

A fase "Método de organização para coleta e análise" foi sistematizada na sequência: localização das fontes e obtenção do material; leitura do material; fichamento; e organização lógica do assunto.

Utilizou-se, inicialmente, a Internet para pesquisar artigos em base de dados do Scholar Google, o Scielo e o banco de teses e dissertações da CAPES. As palavras-chave, nos idiomas português, inglês e espanhol, foram: "Sun Tzu", "conflitos contemporâneos", "estratégia indireta", "abordagem abrangente", “operações interagências”. Essas palavras também orientaram a localização das fontes na Rede Integrada de Bibliotecas do Exército Brasileiro, nas livrarias e nas bibliotecas universitárias.

Para a análise dos dados, foram utilizadas a análise de conteúdo e a triangulação.

A análise de conteúdo foi baseada em Bardin (1977). Passou por três 
19 InterAção

momentos: descrição dos textos; inferência e interpretação dos fatos.

A descrição dos textos teve como passo inicial a leitura flutuante das fontes bibliográficas e da transcrição das entrevistas, buscando selecionar contextos que continham aspectos das categorias da investigação.

A partir do estudo de McNeilly (2009), foram definidas as seguintes categorias: (1) estratégia indireta; (2) conhecimento do inimigo; (3) dissimulação e previsão; (4) tempo; (5) preparação do campo de batalha; (6) liderança.

Os corpora selecionados dos textos e entrevistas foram, então, as unidades de contexto da análise de conteúdo, ou seja, o que imprime significado às categorias de análise (BARDIN, 1977).

Para a inferência, as unidades de contexto foram decompostas em unidades de registro, definindo indicadores (palavras com significado relevante) que permitiram a interpretação das categorias.

Para tanto, foi utilizada a técnica de triangulação ${ }^{7}$, conforme Adorno et al. (apud SOUZA; ZIONI, 2003), para abstrair, de forma reflexiva, o conhecimento entre as perspectivas do resgate crítico da produção teórica, o que resultou na síntese do trabalho.

\section{REVISÃO DA LITERATURA}

\subsection{ABORDAGENS ABRANGENTES: CONCEITOS E ESTRATÉGIAS}

\footnotetext{
7 Adorno et al. (apud SOUZA; ZIONI, 2003) citam que “(...) a proposta da triangulação, atualmente, propõe a sobreposição de uma análise unidimensional, alicerçada em índices da realidade, a uma análise multidimensional (...) A análise realizada através desses pressupostos permite 0 estabelecimento de interrelação entre os fatos, as falas e as ações dos indivíduos, o que permite uma compreensão mais abrangente dos significados" (p. 78).
} 
Segurança é um termo cujo significado tem evoluído historicamente. Em sua perspectiva tradicional e ocidental, Ayoob (1995) conceitua segurança como a proteção contra ameaças externas aos interesses e valores fundamentais do Estado.

Atualmente, Orozco (2011) aborda que o fenômeno da globalização determina uma teorização mais abrangente sobre o assunto. Para Kaldor (1999), deve-se abarcar um contexto em que se manifestam novos tipos de organização da violência, retirando, do Estado, o monopólio do emprego da força. Para Buzan e Hansen (2012), surgem novas abordagens, abrangentes.

O término pacífico da Guerra Fria, o crescimento de conflitos intraestatais, o medo da imigração (...), o meio ambiente em decadência e a aceleração da epidemia de HIV/AIDS demonstravam que o tradicionalismo não estava mais apto a lidar com os desafios da época pós-Guerra Fria (p. 287).

É uma nova visão que teoriza a segurança para além do Estado, não apenas dando ênfase ao setor militar, mas conferindo importância às ameaças domésticas e transfronteiriças (BUZAN; HANSEN, 2012).

Na contemporaneidade, Manwaring (2011) enumera como principais ameaças: 1) atores não estatais hegemônicos (insurgentes, organizações criminosas transnacionais, terroristas); 2) ameaças indiretas à estabilidade e bem-estar do ser humano (pobreza, exclusão social, degradação ambiental).

Se antes o dilema da segurança era: para gerar segurança, deve-se atacar, dominar e aniquilar o oponente para que ele se sinta inseguro (BUZAN; HANSEN, 2012), hoje, esse dilema envolve outras questões: como e por que intervir na proteção de pessoas, em caso de degradação humana flagrante? (MANWARING, 2011). 


\section{InterAção}

Nessa moldura, Manwaring (2011) indica que uma resposta seria modificar o paradigma dos conflitos: mudar do poder de fogo para a informação, tendo como centros de gravidade a opinião pública e a liderança política. Logo, os novos instrumentos do poder seriam: inteligência, diplomacia, mídia, tempo e flexibilidade - estratégias indiretas que, consoante a doutrina brasileira (BRASIL, 2004), buscam a decisão por ações diplomáticas, econômicas e psicológicas.

Na contemporaneidade, Manwaring (2011) enumera como principais ameaças: 1) atores não estatais hegemônicos (insurgentes, organizações criminosas transnacionais, terroristas); 2) ameaças indiretas à estabilidade e bem-estar do ser humano (pobreza, exclusão social, degradação ambiental).

Se antes o dilema da segurança era: para gerar segurança, deve-se atacar, dominar e aniquilar o oponente para que ele se sinta inseguro (BUZAN; HANSEN, 2012), hoje, esse dilema envolve outras questões: como e por que intervir na proteção de pessoas, em caso de degradação humana flagrante? (MANWARING, 2011).

Nessa moldura, Manwaring (2011) indica que uma resposta seria modificar o paradigma dos conflitos: mudar do poder de fogo para a informação, tendo como centros de gravidade a opinião pública e a liderança política. Logo, os novos instrumentos do poder seriam: inteligência, diplomacia, mídia, tempo e flexibilidade - estratégias indiretas que, consoante a doutrina brasileira (BRASIL, 2004), buscam a decisão por ações diplomáticas, econômicas e psicológicas.

Importante, porquanto, revisitar teorias sobre o uso do poder. Dougherty e Pfaltzgraf (1993) definem poder como conjunto de capacidades, militares ou não, que um ator necessita para impor sua vontade. Logo, dependendo de seu 
22 InterAção

poder, certo ator logra (macros)securitizar ${ }^{8}$ temas que lhes são de interesse nas instâncias internacionais, legitimando a ingerência ou o emprego da violência. Ultimamente, são relevantes as considerações de Nye (2006) acerca de hard e soft power.

O hard power consiste na capacidade de um ator alcançar objetivos pelo uso da força militar ou da coerção econômica. Alsina Júnior (2009) ressalta a importância dessa capacidade para a política externa de um Estado, sendo fundamental para dissuasão de ameaças e solução de conflitos.

O soft power é a habilidade que um ator tem de permear outras culturas, mediante persuasão, o que implica estratégias que mesclam elementos simbólicos e culturais com valores políticos, ideológicos e psicossociais, propagando estilo de vida com qualidade e desenvolvimento tecnológico (NYE, 2006). Para Duarte (2012), essa abordagem é baseada em soluções pacíficas, indiretas e sutis, que capacitam um ator a influenciar decisões internacionais.

Corroborando a importância das abordagens abrangentes, a Organização do Tratado do Atlântico Norte (OTAN) destaca que a expressão militar não logra vencer qualquer conflito contemporâneo de forma isolada. Uma aliança internacional deve integrar atores civis e militares, tendo uma compreensão compartilhada dos objetivos gerais e do estado-final desejado. Somente assim se podem delinear processos e estruturas que sejam complementares, de modo que cada militar ou civil colabore com respostas que reforcem, mutuamente, cada esforço (NATO, 2010).

O Brasil também considera essas abordagens contemporâneas, ressaltando a existência de novos atores não estatais e frequentemente

8 Uso da retórica da ameaça subjetiva para levar uma questão para além das políticas normais, justificando a adoção de medidas emergenciais, como emprego da força (BUZAN; HANSEN, 2012). 
23 | InterAção

transnacionais. Portanto, entende que "é necessário um esforço concertado de todos os instrumentos do Poder Nacional - o que inclui forças militares, organizações governamentais (...) e agências civis." (BRASIL, 2013, p. 2-4). Nesse ambiente, chamado interagências, a integração entre militares e civis é essencial.

No Oriente, os militares chineses também estão atentos às novas ameaças, trabalhando em funções não tradicionais, como: desastres naturais, narcotráfico, pirataria, terrorismo (SCOBELL et al., 2011).

Nos Estados Unidos da América (EUA), essas novas abordagens são operacionalizadas pelo conceito de Whole of government (WoG), que postula o emprego de todas as expressões do poder nacional na conjugação de ações de segurança e de desenvolvimento (PAPP, 2012). Isso demanda "esforço holístico, (...) multidimensional, multiorganizacional e multinacional" (MANWARING, 2011, p. 19).

Os desafios do WoG seriam: combater a violência extrema e a contrainsurgência; impedir a proliferação descontrolada de materiais e armas nucleares; sustentar o crescimento econômico, diminuindo impactos climáticos; promover ajuda humanitária; prevenir e solucionar conflitos no mundo (PAPP, 2012).

Conforme seus interesses e sob esse pressuposto, os EUA atuam em todo o globo: combatem o narcotráfico na Colômbia e a violência fundamentalista no Afeganistão, Iraque e Líbia; operam na onda de manifestações e revoltas no mundo árabe e em estados considerados falhados (FRANKE; DORFF, 2012).

Após o atentado das Torres Gêmeas, a demanda estadunidense também 
24 InterAção

legitimou dois conceitos: a guerra pre-emptiva ${ }^{9}$ e preventiva $^{10}$ (BUZAN; HANSEN, 2012; MEI, 2013), o que, por exemplo, contrapõe-se a atores (estatais ou não) que utilizem violência extrema ou que supostamente desrespeitem os direitos humanos.

O que essas abordagens têm a ver com a teoria de Sun Tzu?

\subsection{A ESCOLA ESTRATÉGICA CHINESA E A TEORIA DE SUN TZU}

A filosofia de Sun Tzu sobre a estratégia ressalta aspectos ancestrais que ainda são relevantes às estratégias chinesas, particularmente depois de 1978.

O atual pensamento estratégico chinês é de salvaguarda de seus interesses no mundo. Por meio de seu Livro Branco, a China assegura não procurar a hegemonia. Admite ameaças vindas do exterior e reconhece problemas étnicos internos (Tibete e Xianjiang), razões que determinam a defesa dos interesses marítimos e territoriais, pelos quais conta com mais de um milhão de militares, um porta-aviões, uma Marinha em modernização, mísseis balísticos e de cruzeiro (CHINA, 2013).

Sua estratégia tradicional é de prevenção. Quando isso não é possível, emprega os esforços disponíveis para minimizar gastos materiais e humanos para alcançar uma vitória rápida (MILLER, 2011).

Tal atitude se aproxima ao pensamento de Sun Tzu, que afirmava que campanhas militares não deviam ser demoradas, pois a guerra conduzida de

\footnotetext{
${ }^{9}$ Alguém ataca quando espera ser atacado iminentemente.

${ }^{10}$ A ação ofensiva se baseia na percepção de uma ameaça que possa existir em médio prazo.
} 
25 | InterAção

forma prolongada tende a empobrecer a nação (SUN-ZI, 2001). Ademais, o conceito de tempo na guerra é essencial, porque proporciona quatro vantagens: é um substituto de recursos; surpreende o inimigo; permite explorar fraquezas; e desenvolve o momentum (MCNEILLY, 2009).

Outro pressuposto de Sun Tzu é a preparação do campo de batalha para modelar o inimigo (SUN-ZI, 2001), colocando-o em desvantagem. Nessa mesma perspectiva, os sínicos priorizam relacionar o conhecimento entre as capacidades dos antagonistas. Miller (2011) afirma que a China, tendo conhecimento de suas próprias capacidades, procura aprender o possível sobre as capacidades do rival para modificar sua estratégia. Assim, teria força capaz de influenciar potenciais ameaças em sua periferia e em áreas globais de interesse. Essa situação "parece ter acelerado na última década" (p. 204).

Recobra-se, portanto, o pensamento de Sun Tzu: “Se você conhece o inimigo e conhece a si mesmo, não precisa temer o resultado de cem batalhas" (SUN-ZI, 2001, p. 60).

Nesse sentido, Miller (2011) aborda que, quando a China encontra antagonista mais forte na balança do poder (EUA), toma atitudes que visam a ganhar tempo para desenvolvimento de suas próprias capacidades. Nessas condições, procura realizar medidas conciliadoras em tempo de paz para influenciar a opinião internacional (CHENG, 2011), enfatizando o emprego do soft power. Isso é uma atitude estratégica, considerando que, segundo Duarte (2012), a China não desafia de forma direta o hegemon, porém utiliza ferramentas não militares para equilibrar o poder, retardando as políticas da superpotência.

Ademais, Duarte assevera que o choque frontal com grandes potências pode ser extremamente danoso para os objetivos chineses. Sabendo que suas 
26 | InterAção

forças armadas não combatem regularmente desde 1979 e que sua frota de submarinos não possui qualquer experiência (SCOBELL et al., 2011), Pequim valoriza o postulado de Sun Tzu de que uma nação deve saber quando não tem condições de lutar (KANE, 2007).

Nessa lógica, a China busca mitigar essas debilidades, procurando observar os conflitos atuais, colhendo ensinamentos para suas estratégias (SCOBELL et al., 2011). Valoriza, assim, a teoria de Sun Tzu de que "a guerra é um assunto de vital importância para o Estado (...). É imperativo que seja estudada" (MCNEILLY, 2009, p. 25).

Desses ensinamentos, Cheng (2011) ressalta que os sínicos perceberam que as novas guerras são locais e empregam avançada tecnologia de informação integrada a modernos sistemas aeroespaciais e de armas. Destaca-se ainda a atenção chinesa à guerra psicológica, à opinião pública e ao Direito (internacional e nacional). Para enfrentar essas renovações, a estratégia chinesa prioriza as operações de informação ${ }^{11}$. Os avanços chineses no campo da cibernética corroboram essa tendência e ratificam, conforme McNeilly (2009), o pensamento de Sun Tzu de que, para vencer a atual guerra da informação, “tudo deve ser conhecido" (p. 113).

Nesse sentido, os chineses também analisam as capacidades do Comando Militar dos EUA no Pacífico (PACOM), que está pronto para combater qualquer contingência na Ásia.

Há correlação dessa hipótese com a teoria de Sun Tzu, que afirmava que se uma tropa estrangeira permanece nas proximidades, é porque tem real intenção de avançar (SUN-ZI, 2001). Isso ganha relevância com as considerações

11 Integra avançadas capacidades das operações psicológicas, comunicação social, comando e controle, inteligência e uso da cibernética (BRASIL, 2013). 
27 InterAção

de Iglesias (2012), que argumenta que a atual administração estadunidense ratificou o compromisso com seus aliados asiáticos quando priorizou a Ásia em sua política externa.

Sabendo dos postulados preventivos e pre-emptivos por parte dos EUA, a China, país onde o respeito aos direitos humanos pode ser considerado questionável, adota estratégias indiretas que busquem frustrar a possibilidade de interferência do PACOM sobre suas metas (MILLER, 2011).

Ademais, Pequim procura se inserir nos diversos arranjos regionais e mundiais. Para isso, emprega tropas e observadores militares em missões de paz, realiza operações humanitárias e exercícios militares com vizinhos, bem como intercâmbios com o próprio PACOM (MILLER, 2011).

Verifica-se, portanto, que a ênfase chinesa no soft power se deve à necessidade de persuadir a opinião pública internacional para que obtenham aliados em caso de conflito. Essa atitude se aproxima à filosofia de Sun Tzu de examinar a questão das alianças do inimigo, fazendo com que sejam rompidas e dissolvidas (SUN-ZI, 2001).

Nota-se também que sua priorização em estratégias indiretas busca o equilíbrio do poder. Esse fato também converge à teoria de Sun Tzu, em que "o ótimo seria dominar o inimigo sem chegar a batalhar com seu exército" (SUNZI, 2001, p. 57).

A postura chinesa é diferente quando ela compete, em qualquer campo do poder, com países de menor projeção. Miller (2011) afirma que, nesse contexto, as políticas chinesas buscam demonstrar capacidades de coação, ou seja, a China atua com hard power. Isso converge à ideia de Sun Tzu de que aquele que conhece a arte do método direto e do indireto será vitorioso (SUNZI, 2001). 
28 InterAção

Essa postura é estimada no âmbito regional (PETRY, 2013), fazendo com que o Japão (MANWARING, 2011) e os EUA (CHENG, 2011) percebam, em seus cenários prospectivos, que a China se prepara para o emprego direto da expressão militar. Esse fato gerador de futuro, caso ocorra, vai ao encontro de seus pensamentos ancestrais, pois "inspirados pelos ensinamentos de Sun Tzu, os chineses 'só partem para a batalha quando estão seguros que irão vencê-la'" (DUARTE, 2012, p. 511).

Por oportuno, cabe destacar que Sun Tzu valoriza aspectos da liderança militar, destacando que o objetivo principal do comando, organização e comunicações é aumentar o controle do comandante supremo sobre suas forças e reduzir suas preocupações administrativas (KANE, 2007).

Em face do exposto e corroborando a análise de McNeilly (2009), inferem-se os seguintes campos de contribuições de Sun Tzu para a estratégia militar: estratégia indireta; conhecimento do inimigo; dissimulação e previsão; tempo; preparação do campo de batalha; liderança. Como os conflitos contemporâneos valorizam esses postulados?

\section{APRESENTAÇÃO DOS RESULTADOS}

Esta seção está organizada conforme as categorias da investigação. As unidades de contexto são as citações e as respostas dos entrevistados. Os indicadores foram grifados em negrito.

\subsection{ESTRATÉGIA INDIRETA}


29 | InterAção

O emprego contemporâneo estadunidense valoriza a utilização da estratégia indireta, como ocorreu na Primeira Guerra do Golfo, em 1991:

A coalizão (...) isolou o Iraque, impondo-lhe um bloqueio comercial. Estas sanções permaneceram mesmo após o fim da guerra. (...) O Iraque foi, portanto, submetido sob todos os aspectos, econômica e diplomaticamente (...) mesmo antes que as hostilidades começassem (CHENG, 2011, p. 164).

Pequim, inclusive em sua atuação regional, visualiza o emprego de estratégias indiretas:

A China quer Taiwan intacta, não é do seu interesse disparar indiscriminadamente mísseis que causem destruição em massa (SCOBELL et al., 2011, p. 13).

Nas entrevistas, foi ressaltado o seguinte:

M1: No caso dos conflitos psicológicos e nos cenários de guerra (...) (contemporâneos), (a estratégia indireta) se aplica plenamente. (...) Quanto às grandes potências, (...) o medo do holocausto nuclear tem sido mais efetivo do que o preceito de Clausewitz.

M2: Nos conflitos contemporâneos (...) (o emprego de estratégias indiretas) é importante, pois as guerras não ocorrem mais em espaços vazios. As estratégias diretas tendem a potencializar os efeitos colaterais, causando desgaste perante a opinião pública, tirando a liberdade de ação em todos os níveis.

M3: Na pretensão de separação do País Basco da Espanha, há emprego de estratégia indireta para solução do conflito por parte do Estado espanhol (...) Os Estados Unidos (...) só aplicam a doutrina preventiva (...) quando têm certeza da vitória. As outras potenciais ameaças, Irã e Coréia do Norte, apenas foram atacadas com ações diplomáticas e embargos econômicos.

M5: As insurgências armadas no Oriente Médio demonstram que até mesmo uma superpotência como os EUA pode cometer erros (...) ao tentar derrubar e substituir um regime. No Afeganistão, os EUA e os seus aliados têm dificuldade para eliminar o Taliban e os seus vínculos com o Al Qaeda, que, 
30 InterAção

apesar de serem grupos relativamente pequenos, são organizados em células, tornando o emprego tradicional das forças armadas inadequado. No caso da Síria (...) os EUA sabem que existe a possibilidade real de se envolverem em um conflito mais prolongado, e de resultado incerto.

Nota-se, portanto, que o emprego de estratégias indiretas também é significativo para evitar o uso da violência extrema, para conferir maior eficácia às campanhas, para mitigar danos colaterais e, não menos importante, para evitar a perda do apoio da opinião pública local, nacional e internacional. É também uma alternativa frente à falta de outras opções estratégicas. Isso converge ao aforismo de Sun Tzu de que uma nação deve saber quando não tem condições de lutar, não olvidando ainda seu pensamento de que é pela combinação das estratégias direta e indireta é que se alcança a vitória.

\subsection{CONHECIMENTO DO INIMIGO}

A não observância desse princípio de Sun Tzu pode levar a perdas de vidas e de recursos inestimáveis. Um exemplo ocorreu na Chechênia:

O General Yang Hui (...) destacou os principais problemas: a falta de cálculo da capacidade de lutar dos chechenos, a quase ausência de inteligência sobre o inimigo (SCOBELL et al., 2011, p. 18).

No combate a ameaças como o narcotráfico, as capacidades da força oponente são potencializadas por sua nova organização.

Na sequência do desmantelamento dos cartéis (...) na década de 1990, o tráfico de drogas colombiano mudou para uma rede descentralizada de várias centenas de grupos menores, espalhando suas atividades de forma ampliada e tornando suas operações menos vulneráveis às abordagens tradicionais (BOUSQUET, 2008, p. 915-916). 
31 InterAção

Essas características alavancam a necessidade de se conhecer o oponente, diferenciando-o da população. A experiência estadunidense na Macedônia confirma essa ideia, onde enfrentou uma guerrilha "que usava a população local para dificultar o reconhecimento das forças militares" (USAIS, 2005, p. $48)$.

A atual doutrina militar brasileira também ratifica essa complexidade, "que reduz a possibilidade de identificar o oponente, requerendo novas capacidades de combate para evitar efeitos colaterais"' (BRASIL, 2013, p. 2-1).

Na entrevista, M1 asseverou que “a filosofia de Sun Tzu (...) me parece uma lei das relações humanas". Hodiernamente, essa consideração é essencial, já que a morte de não combatentes é muito prejudicial para a imagem do Estado em conflito.

Por sua parte, M4 e M5 ressaltaram a importância das normas internacionais nesse sentido:

M4: A própria evolução do direito internacional indica uma tendência em se evitar o conflito armado para a solução de controvérsias. O desenvolvimento de conceitos como o de soft power dá indicação semelhante.

M5: Nos conflitos contemporâneos, a prevenção e a mediação permanecem fundamentais, pois a capacidade militar, mesmo dos países que não possuem armas nucleares, tornou-se tamanha que os conflitos têm o potencial de causar destruição. (...) O regime internacional de segurança, inclusive os mecanismos da ONU, priorizam a prevenção e mediação de conflitos.

O conhecimento do inimigo, tal como teorizava Sun Tzu, é a base para o sucesso na batalha. Ressignificando sua assertiva para o atual contexto dos conflitos, esse conhecimento também é chave para a prevenção dos danos colaterais e, inclusive, para a legitimação das ações dos Estados que evoluam 
32 | InterAção

para o emprego do hard power.

\subsection{DISSIMULAÇÃO E PREVISÃO}

Esses postulados, segundo McNeilly (2009), são muito importantes para a vitória na guerra da informação.

Na Guerra do Kosovo, a atenção à previsão na inteligência e na logística foi relevante para o êxito nas operações de informação:

O exército chinês observou muitos aspectos da operação militar estadunidense no Kosovo, (...), a campanha aérea, emprego de munições guiadas com precisão, e as operações de informação. Estão incluídos, (...), apoio logístico e ressuprimento de equipamentos militares, transporte militar, mobilização de forças de reserva, guerra psicológica e de relações públicas, uso de veículos aéreos não tripulados (SCOBELL et al.; 2011; p.10).

Na Segunda Guerra do Golfo, foi notável a importância dada às operações de informação:

Quando do início do interesse em operações conjuntas (...) Baocun (...) nota cinco áreas investigadas pelo exército:

1. Comando, controle, comunicações, computação e modernização da inteligência; (...)

3. Treinamento de pessoal em operações de informação;

4. Condução de exercícios de informação;

5. Introdução de equipamento informatizado. (CHENG, 2011, p. 165).

Foi ainda significativo o cuidado norte-americano com as infraestruturas de comunicações no Iraque. Por quê?

Os EUA, no Iraque, não destruíam (...) as comunicações iraquianas e infraestrutura de transmissão (...). Em vez disso, 
33 | InterAção

essas instalações foram autorizadas a permanecer no ar, para que os EUA pudessem explorar suas frequências para transmitir mensagens dissimuladas e informações imprecisas para dissociar a coesão social. (...) (Isso) também permitiu que os EUA afirmassem que foi uma guerra 'limpa', já que isso era motivo de transparência (CHENG, 2011, p. 180).

Logo, a preservação da infraestrutura iraquiana foi essencial para a condução de operações psicológicas e para a legitimação da opinião internacional favorável.

Nas entrevistas, destacou-se o seguinte:

M2: A dissimulação e a previsão também se mantêm válidas. Contudo, (...) a questão hoje está (...) (n)o alvo da ação de dissimulação. Vamos usar (...) a Guerra do Iraque, (...), (que) abrangeu duas fases distintas: a operacional $e$ a de estabilização. $\mathrm{Na}$ primeira fase, $\mathrm{o}$ alvo era $\mathrm{o}$ inimigo convencional, e, nesse caso, havia justificativas para que a opinião pública fosse também iludida, pela evidência do que contribuiria para o esforço de guerra. (...)

(Na) segunda fase, guerra entre o povo, ou de estabilização (...) quem seria o alvo? Havia uma multiplicidade de atores envolvidos (...). A utilização pouco criteriosa desses expedientes pode produzir efeitos negativos, gerando desgaste e perda de credibilidade, a qual, por sua vez, é um importante objetivo a ser conquistado e mantido.

M3: A dissimulação e previsão são técnicas utilizadas para evitar o ressurgimento de antagonismos históricos, principalmente nos blocos da América do Sul e Ásia.

M4: A aplicação de tais técnicas ganha impulso com os avanços tecnológicos recentes. As facilidades viriam acompanhadas de uma maior complexidade na configuração das estratégias.

O impulso dos avanços tecnológicos, empregada não somente em ações cinéticas, mas também como instrumento de engenharia social, foi destaque também na Primavera Árabe, quando as redes sociais foram utilizadas para comoção da opinião pública. 
34 | InterAção

Por seu turno, M5 relacionou os postulados de dissimulação e previsão à abordagem abrangente:

M5: No período pós-guerra fria, tornou-se ainda mais essencial investir nas capacidades de dissimulação e de previsão através do conhecimento multidimensional dos interesses e capacidades dos Estados, assim como atores não estatais. Isso requer compreender não apenas a estratégia militar, mas também o contexto econômico, político e cultural no qual operam tais atores, pois todos esses elementos contribuem para estruturas as suas ações e decisões.

Destarte, esse novo olhar sobre os postulados de Sun Tzu sobre previsão e dissimulação é altamente significativo para o êxito nas operações de informação e a consequente legitimação internacional.

\subsection{TEMPO}

A OTAN, em suas diretrizes para os atuais conflitos, considera a relevância do fator tempo para a tomada de decisões estratégicas:

A globalização do mundo, através de meios cada vez mais eficazes de transporte, de comunicações, de acordos multilaterais e arranjos políticos, também levou à necessidade de agir e reagir rapidamente. $O$ tempo tem se tornado um elemento essencial no cada vez mais complicado processo de tomada de decisão (NATO, 2010, p. 1-1).

Colin Powell, Chefe do Estado-Maior Conjunto dos EUA na Primeira Guerra do Golfo, relacionou a utilização do tempo ao princípio da 
35 | InterAção

oportunidade:

(...) tome a decisão quando dispuser de cerca de sessenta por cento das informações. Tomar uma decisão em qualquer momento além disso pode fazer com que a oportunidade desapareça (MCNEILLY, 2009, p. 156).

Depois de 11 de setembro de 2001, a análise estadunidense destaca a importância do aproveitamento do tempo para obter opinião internacional favorável:

À medida que lutamos contra a guerra global contra o terror, os nossos líderes devem ser capazes de implantar, em qualquer lugar e em curto prazo, a divulgação institucional em cenários que vão desde as operações de estabilidade e reconstrução até as principais operações de combate (USAIS, 2005, p. iv).

Por oportuno, cabe ressaltar que, muitas vezes, o importante é ganhar tempo, particularmente quando se priorizam estratégias indiretas:

O tempo não é perdido porque ele sempre retorna (...). Como forma de contrapor o atraso tecnológico da sua marinha (...), a China está gradualmente substituindo as velhas unidades costeiras por navios mais modernos (...) que lhe permite(m) cumprir suas ambições regionais e (...) colocar a China entre as grandes potências navais (DUARTE, 2012, p. 504-510).

Corrobora-se, portanto, a importância desse postulado milenar na contemporaneidade, afinal Sun Tzu aforava que o prolongamento de qualquer guerra no tempo tende a empobrecer a nação. Ainda mais com o alto custo dos atuais materiais militares.

\subsection{PREPARAÇÃO DO CAMPO DE BATALHA}

Como já visto anteriormente, as novas ameaças se apresentam de forma 
36 | InterAção

difusa, o que traz consequências para a preparação do campo de batalha. As recentes experiências estadunidenses ratificam essas novas tendências.

Desde 1990, as operações estão ocorrendo em áreas que tradicionalmente eram evitadas. Não pode ser mais um desafio operar nas montanhas do Afeganistão (...) ou as áreas urbanas complexas do Oriente Médio. Nossas forças na Somália, no Afeganistão e no Iraque, conseguiram enfrentar o inimigo nessas regiões inóspitas, em grande parte, por causa da sua capacidade de analisar o terreno e usá-lo em proveito próprio (USAIS, 2005, p. 65).

M5 também destacou novas consequências:

O surgimento de novas tecnologias bélicas, tais como VANTs (veículos aéreos não tripulados), alteram a noção de campo de guerra e dificultam a proteção de civis.

Destarte, as abordagens abrangentes passaram a exigir dos atores estatais o desenvolvimento de novas doutrinas de segurança e defesa, com o enfoque cada vez mais holístico, conjugando as diversas formas de poder, tal como preconiza o WoG, já que "carteis de drogas, organizações terroristas e outros extremistas tendem se estabelecer em áreas onde o Estado é fraco e incapaz de manter o controle" (FRANKE; DORFF, 2012, p. 36). Logo, a consecução do WoG demanda modelar as infraestruturas e os serviços essenciais locais, determinando trabalho conjugado entre civis e militares (o terreno humano), até mesmo para garantir a proteção da população local.

No Afeganistão, a parceria civil-militar consistiu na formação de equipes interagências com a participação afegã. A missão era facilitar o compartilhamento de informações entre os diversos órgãos, fortalecer o Exército Nacional e as autoridades policiais locais, bem como reconstruir e melhorar a infraestrutura local (FLAVIN, 2004).

O Brasil, nas ações de estabilização no Haiti, tem percebido a necessidade 
37 InterAção

de modelar o terreno.

No âmbito da própria MINUSTAH, a conquista de Belair representou a possibilidade da Missão se articular efetivamente em um perfil multifuncional. (...) Os atores civis foram enfaticamente convidados pelo componente militar, em cuja leitura do ambiente figurava uma imperativa necessidade de inserção do braço assistencial da ONU e do Estado haitiano para consolidar a paz. (PACHECO et al., 2013, p. 7).

Observa-se, portanto, que, no moderno conceito de WoG, o postulado de Sun Tzu ganhou novo significado: modelar o terreno depende de ações multidimensionais, perpassando a expressão militar.

\subsection{LIDERANÇA}

Segundo McNeilly (2009), um exemplo prático de aplicação da importância das ideias de Sun Tzu sobre liderança é a crescente valorização, em diversos países, de conceitos como o de "estado final desejado" nos planejamentos, denotando a necessidade do conhecimento das principais diretrizes do líder por todos os escalões.

A não observância desses pressupostos pode resultar em graves óbices, como indica o insucesso russo na Chechênia:

O General Yang Hui (...) destacou os principais problemas: falta de acordo entre os altos dirigentes russos sobre o que fazer com o movimento de independência checheno, (...) falta de preparo dos militares em conduzir a primeira Guerra da Chechênia (SCOBELL et al., 2011, p. 18).

Nas entrevistas, foi possível inferir a importância da liderança estratégica para a consecução dos objetivos nacionais na Primeira Guerra do Golfo. 
M2: A baixa em combate deixou de ser um pressuposto básico (síndrome do saco preto) e as decisões (...) passaram a ser fortemente condicionadas pela garantia da inexistência de perdas de qualquer natureza. Um exemplo (...) foi dado pelo Gen Schwarzkopf. O Presidente Bush e o Gen Colin Powel, pressionados pela opinião pública, diariamente exigiam que ele iniciasse (...) ofensiva. O Gen resistiu (...) até que tivesse reunido todo poder de combate necessário para cumprir sua missão com o mínimo de baixas.

Além da liderança, nota-se que o General valorizou outro ensinamento de Sun Tzu: os guerreiros somente avançam quando têm certeza da vitória (DUARTE, 2012).

\section{CONCLUSÃO}

O poder militar de um país deve ser empregado de acordo com objetivos estratégicos orientados pelo nível político, visando a dar suporte a um determinado anseio dessa sociedade. Essa forma de empregar a força pode variar dentro de um espectro que vai de uma simples pressão diplomática até o enfrentamento bélico propriamente dito. De forma geral, Sun Tzu buscava a vitória sem combater e seus preceitos teóricos influenciaram diversos estrategistas ao longo da história militar.

Em síntese, após uma análise dos principais conflitos contemporâneos sob a óptica da teoria de Sun Tzu, pode-se verificar que as novas abordagens sobre os temas de defesa ampliam ainda mais sua aplicabilidade, revelando-se determinante para o sucesso militar de um Estado em um momento de crise no atual cenário.

A estratégia indireta é um dos preceitos milenares mais consagrados e consiste em vencer o inimigo sem lutar. É empregada de forma recorrente nas 
39 | InterAção

relações internacionais, quando presente algum conflito de interesses. A poderosa China tenta mostrar ao mundo que não tem ambições hegemônicas e se esforça para convencer o sistema internacional de sua vocação pacífica. De modo semelhante, as potências ocidentais a utilizam para amparar suas intenções no concerto das nações. Só o tempo irá demonstrar se a priorização da projeção do soft power não é apenas um estágio antes de uma guinada para o hard power.

O conhecimento do inimigo juntamente com a dissimulação e a previsão convergem no sentido de demonstrar que não se pode combater sem saber todas as suas capacidades. Nos conflitos contemporâneos, a ênfase da capacitação para as operações de informação é fundamental para conquistar as opiniões públicas, nacional e internacional, contribuindo para aumentar a liberdade de ação do Estado. Essas características permeiam de forma marcante as doutrinas estadunidenses, chinesas e da OTAN.

A preparação do campo de batalha e o fator tempo continuam sendo uma necessidade para se conseguir o sucesso em um combate na atualidade. Entretanto, devido à presença de novos atores em um campo de batalha, é vital a conjugação de todos os recursos disponíveis. Assim, o militar não deve prescindir de qualquer meio ou pessoal que possa lhe trazer uma vantagem nesse ambiente incerto. Dessa forma, operações interagências, conduzidas de forma oportuna, vão ao encontro desse preceito chinês e estão presentes nas doutrinas da maioria dos exércitos da atualidade.

A liderança era extremamente priorizada na milenar doutrina chinesa, pois o comandante que a possuísse conseguiria extrair o máximo de seus comandados, multiplicando o seu poder de combate. Atualmente, a ideia-força desse preceito é ainda alavancada pelos avanços tecnológicos, o que traz 
40 InterAção

importantes contribuições ao Comando e Controle.

Por fim, pôde-se constatar que a estratégia militar foi modernizada ao longo da história, principalmente pela incorporação de novas tecnologias agregadas aos meios à disposição de um exército. Entretanto, alguns preceitos tradicionais não se modificaram, apenas foram adaptados ao novo ambiente. Nesse contexto, insere-se a estratégia milenar do mestre Sun Tzu, que permanece atual depois de mais de 2500 anos.

\section{REFERÊNCIAS}

ALSINA JÚNIOR, João P. S. O poder militar como instrumento da política externa brasileira contemporânea. Revista Brasileira de Política Internacional, 52 (2), 2009. p. 173-191.

AYOOB, M. The Third World security predicament. Boulder: Lynne Reinner Publishers, 1995.

BARDIN, L. Análise de conteúdo. Lisboa: Edições 70, 1977.

BAUMAN, Z. La sociedad sitiada. Buenos Aires, Fondo de Cultura Económica Argentina, 2004.

BRASIL. Exército Brasileiro. Estado-Maior do Exército. C 124-1: Estratégia. 4. ed. Brasília-DF: EGCCF, 2004.

EB.20-MC-10-201: operações em ambiente interagências. Brasília-DF: EGCCF, 2013.

BOUSQUET, Antoine. Chaoplexic warfare or the future of military organization. International Affairs, 84, 5, 2008. p. 915-929.

The scientific way of warfare: order and chaos on the battlefields of modernity. New York: Columbia Univ. Press, 2009.

BUZAN, Barry et al. Security: a new framework for analysis. Boulder: Lynne Rienner Publishers Inc., 1998. 
41 InterAção

; HANSEN, L. A evolução dos estudos de segurança internacional. São Paulo: UNESP, 2012.

CHENG, Dean. Chinese Lessons from the Gulf Wars. In: SCOBELL A. et al. (orgs.). Chinese lessons from other people's war. Carlisle: Strategic Studies Institute, 2011. p. 153-200.

CHINA. Embaixada da China no Brasil. Governo chinês divulga livro branco sobre defesa nacional. Tradução de Lucas Xu. Revisão de João Pimenta. Disponível em: <http://br.china-embassy.org/por/szxw/t1031694.htm>. Acesso em: 24 jul. 2013.

DOUGHERTY, J.; PFALTZGRAF, R. El poder y la teoría realista. Teorías en pugna en las relaciones internacionales. Buenos Aires: Grupo Latinoamericano, 1993.

DUARTE, Paulo. Soft China: o caráter evolutivo da estratégica de charme chinesa. Contexto internacional (PUC), vol. 34, n. 2, jul.-dez. 2012. Disponível em: <http:/ / contextointernacional.iri.puc-rio.br/media/5artigo342.pdf>. Acesso em: 12 jul. 2013.

FLAVIN, William. Civil military operations: Afghanistan. Observations on civil military operations during the first year of Operation Enduring Freedom. Carlisle: PKASOI, 2004. Disponível em:

<http:// pksoi.army.mil/PKM/publications/>. Acesso em: 22 jul. 2013.

FRANKE, V. C.; DORFF, R. H. (orgs.) Conflict management and whole of government: useful tools for U.S. National Security? Carlisle: Strategic Studies Institute, 2011.

FRIGOTTO, G. O enfoque da dialética materialista histórica na pesquisa educacional. In: FAZENDA, I. (org.). Metodologias da Pesquisa Educacional. 11. ed. São Paulo: Cortez, 2008.

IGLESIAS, M. L. Tensiones en el Mar de China Meridional. In: INSTITUTO ESPAÑOL DE ESTUDOS ESTRATÉGICOS, Documento Análisis, 33/2012. Disponível em: <http://www.ieee.es/Galerias/fichero/docs_analisis L2012/DIEEEA33-2012_TensionesMarChina_MLI.pdf>. Acesso em: 22 jul. 2013.

KALDOR, Mary. New and old wars: organized violence in a global era. Stanford: Stanford University Press, 1999.

KANE, Thomas N. Ancient China on Postmodern war: enduring ideas from the Chinese strategic tradition. Oxon: Routledge, 2007. 
42 InterAção

KEOHANE, R. The globalization of informal violence, theories of world politics and the "liberalism of fear". Dialogue IO, v. 1, Issue 1, jan. 2002. p 29 - 43.

Disponível em:

$<$ http: //journals.cambridge.org/action/displayAbstract?fromPage=online\&aid =149065>. Acesso em: 22 dez. 2012.

LEITE, Márcio D. A. Planejamento estratégico das Forças Armadas baseado em capacidades: reflexos para o Exército Brasileiro. Coleção Meira Mattos, $n^{\circ} 24,3^{\circ}$ quadrimestre 2011, Rio de Janeiro, 2011. Disponível em:

<http://www.eceme.ensino.eb.br/meiramattos/index.php/RMM/article/vie $\underline{\mathrm{w} / 77 / 104}>$. Acesso em: 27 jul. 2013.

MANWARING, Max G. The strategic logic of the contemporary security dilemma. Carlisle: Strategic Studies Institute, 2011.

MARCONI, M. A.; LAKATOS, E. M. Fundamentos de metodologia científica. 5. ed. São Paulo: Atlas, 2003.

MCNEILLY, Mark. Sun Tzu e a arte da guerra moderna. 4. ed. Tradução de Luiz Silva. Rio de Janeiro: Record, 2009.

MEI, Eduardo. Estado, Guerra e violência: as "novas guerras" e suas implicações ara a teoria clausewitziana da guerra. In: __ ; SAINT-PIERRE, Hector L. (orgs.). Paz e guerra: defesa e segurança entre as nações. São Paulo: UNESP, 2013.

MILLER, Frank. The People's Liberation Army Lessons Learned from Recent Pacific Command Operations and Contingencies. In: SCOBELL A. et al. (orgs.). Chinese lessons from other people's war. Carlisle: Strategic Studies Institute, 2011. p. 201-236.

NATO (North Atlantic Threat Organization). Comprehensive operations planning directive. Brussels: NATO, 2010.

NYE, Joseph. Soft power: the means to success in world politics. Cambridge: Perseus Books Group, 2006.

OROZCO, G. Securitización en tiempos de globalización. In: GODOY et al. Construyendo lo global. Barranquila: Universidad del Norte, 2011.

PACHECO, Fábio C. et al. A interação militar ao ambiente interorganizacional de uma missão de paz: o estudo da MINUSTAH. Coleção Meira Mattos, $\mathrm{n}^{\circ} 28$, $1^{\text {o }}$ quadrimestre 2013, Rio de Janeiro, 2013. Disponível em: <http://www.eceme.ensino.eb.br/meiramattos/index.php/RMM/article/vie w/172/258>. Acesso em: 01 ago. 2013. 
43 | InterAção

PAPP, Daniel S. The whole of government approch to security and beyond. In: FRANKE, V. C.; DORFF, R. H. (orgs.) Conflict management and whole of government: useful tools for U.S. National Security? Carlisle: Strategic Studies Institute, 2011.

PETRY, André. O século do Pacífico. Veja, v. 2.318, abril, 2013. p. 110-113.

PIZARRO Leóngomez, E. Uma democracia sitiada. Rio de Janeiro: Bibliex, 2006.

SAINT-PIERRE, H. Grandes tendências da segurança internacional contemporânea. In JOBIM, N. et al. Segurança Internacional: Perspectivas brasileiras. Rio de Janeiro: FGV, 2010. p. 31-48.

SCOBELL A. et al. (orgs.). Chinese lessons from other people's war. Carlisle: Strategic Studies Institute, 2011.

SOUZA, D. V.; ZIONI, F. Novas perspectivas de análise em investigações sobre meio ambiente: a teoria das Representações Sociais e a técnica qualitativa da triangulação de dados. Saúde soc., São Paulo, v. 12, n. 2, Dec. 2003. Disponível em <http:/ / dx.doi.org/10.1590/S0104-12902003000200008>. Acesso em 15 Mar. 2013.

SUN-ZI. El arte de la guerra. Edición de Fernando Puell. Madrid: Biblioteca Nueva, 2001.

USAIS (United States Army Infantry School). Infantry in battle: from Somalia to the Global War on Terror. Fort Benning: USAIS, 2005.

VISACRO, A. Guerra irregular: terrorismo, guerrilha e movimentos de resistência ao longo da história. São Paulo: Contexto, 2009. 